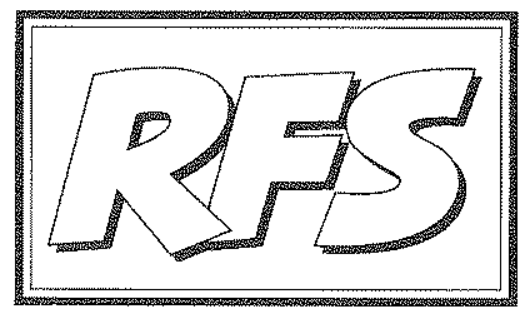

Revista de Fomento Social, 51 (1996), 445468

\title{
Aportaciones de la teología de la liberación al pensamiento social cristiano
}

El objeto de este trabajo es rememorar una contribución del pensamiento cristiano, conocida como teología de la liberación, al planteamiento, análisis y propuesta de solución de los problemas sociales. El autor presenta una concepción del pensamiento social cristiano más amplia que la tradicional «doctrina social de la Iglesia»: las propuestas de comprensión y solución de los problemas sociales inspiradas en el cristianismo. Comienza por una consideración sobre lo que son los problemas sociales, de los marcos de comprensión y solución de los mismos y del significado que en ese marco tienen las propuestas inspiradas en el cristianismo. Analiza luego algunas dificultades que ello ha encontrado y encuentra actualmente. Presenta después una caracterización de la teología de la liberación, para sintetizar cuáles son sus principales aportaciones al pensamiento social cristiano, así como algunas de sus limitaciones.

Rafael YUSTE MOYANO S.J.(*)

(*) Profesor de Ética y Pensamiento Social Cristianoen la Facultad de Ciencias Económicas y 


\section{Los problemas sociales y el pensamiento cristiano}

\section{Los problemas sociales}

Históricamente se ha hablado del problema social entendido comoel problema de la justicia en las relaciones socioeconómicas, de las desigualdades sociales y de las condiciones injustas en las relaciones de trabajo. Ese ha sido el problema social por excelencia. Hoy la gama de lo que entendemos por problemas sociales se ha ampliado considerablemente. El mismo problema social tradicional se entiende hoy, preferentemente, como el problema originado por la desigualdad entre los países ricos y los países pobres, ya que es ahí donde más crudamente manifiestan su injusticia las relaciones socieconómicas. La persistencia de la pobreza y la muerte que ella acarrea, junto a la percepción de que hoy sería posible erradicarla, ése es, a nuestro juicio, el gran problema de nuestra sociedad actual a nivel mundial.

De otra parte, hoy existe mayor conciencia de que los problemas sociales son interdependientes y su solución sólo puede ser global. Solucionar el problema de la pobreza en una región del mundo está instrumental y políticamente ligado a cambios y problemas en la práctica totalidad de las demás regiones. Solucionar el problema de la pobreza es, además, intentar solucionar la totalidad de los problemas sociales. La pobreza es, a la vez, origen y consecuencia de los otros problemas sociales que acucian hoy a la humanidad: el crecimiento demográfico, el desempleo, las migraciones, el deterioro ecológico y su relación con el crecimiento económico, las guerras y el armamentismo, las desigualdades opresivas que enfrentan diversos colectivos (socioeconómicos, étnicos, culturales, sexuales), la droga, las enfermedades contagiosas, etc.

Finalmente, existe hoy el convencimiento de que los problemas sociales son problemas muy complejos (a la vez problemas sociales, económicos, técnicos, culturales y, sobre todo, políticos). Los problemas sociales no son comprensibles ni, sobre todo, solucionables al margen de la política.

Pero los problemas sociales tienen también una dimensión ética, que lleva a comprenderlos, no como meras situaciones de hecho, de cuya existencia o

Empresariales (ETEA), Universidad de Córdoba. Doctorado en Fitosofía con la tesis «Dimensión filosófica de la Teología de la Liberación». 
gravedad nadie fuera culpable, sino como situaciones injustas, producidas o agravadas por causas atribuíbles a la libre conducta humana. Son, por tanto, situaciones de cuya existencia o gravedad y de cuya solución o no, existe, al menos en parte, una responsabilidad individual y colectiva o política.

Dimensión ética que urge a la solución de tales problemas, que apremia la responsabilidad individual y colectiva y la voluntad política, que urge los cambios estructurales y las medidas técnicas necesarias para erradicar las causas que producen o agravan las situaciones injustas.

A la vez, la dimensión ética exige encauzar tanto la comprensión como los intentos de solución de los problemas sociales por vías acordes con el respeto a la dignidad de la persona.

Por fin, es tarea ética denunciar tales situaciones injustas y la responsabilidad sobre las mismas, o las soluciones insuficientes o no respetuosas con la dignidad de las personas.

\section{Pensamiento cristiano sobre los problemas sociales}

Tradicionalmente se ha entendido por pensamiento social cristiano la «doctrina social de la Iglesia», y por ésta las encíclicas de los papas sobre los problemas sociales. Cuando aquí hablamos del pensamiento social cristiano lo entendemos en un sentido más amplio: todas las propuestas de comprensión y solución de los problemas sociales que tienen una inspiración en el cristianismo.

\section{a) Algunas dificultades}

En amplios sectores de nuestra sociedad, un discurso en el que el pensamiento cristiano y los problemas sociales, religión y política, aparecen interrelacionados despierta una comprensible cautela. Cautela que nace, unas veces, del recuerdo histórico de formas de interrelación conocidas como cristiandad, clericalismo o la más reciente de nuestro nacionalcatolicismo. Es decir, una cautela que tiene su origen en el rechazo a la tradicional legitimación religiosa del poder. En aquellas formas, la interrelación supuso una tutela cultural ejercida por las iglesias, desde el poder o al amparo y sombra del mismo.

En otros, en algunos creyentes y jerarquías de iglesias, la cautela nace del miedo a la división interna, dada la pluralidad de opciones ideológicas y partidistas 
que concurren en lo político en una sociedad democrática. La neutralidad, el apartidismo e incluso el imposible apoliticismo, son con frecuencia invocados en función de preservar dicha unidad de las iglesias. Lo propio de las iglesias parecería reservarse para un papel de orientación, crítica o asesoramiento de la política desde los postulados de la moral religiosa.

Naturalmente, tales cautelas son dificiles de disipar racionalmente porque anidan en experiencias que pertenecen a la memoria colectiva o en prejuicios siempre confirmables con tal o cual caso o experiencia. Hoy, sin embargo, parece que tales cautelas serían, por lo menos, excesivas. En nuestra sociedad, la teoría y la acción políticas no están amenazadas en su autonomía por la tutela de las iglesias. Tampoco, en nuestra sociedad, el pluralismo y la diversidad de opciones políticas entre los creyentes son vividas, a excepción de por algunos, con la dramática percepción de que hagan peligrar la unidad de las iglesias.

En la actualidad, otra rémora pesa más fuertemente sobre el pensamiento que quiera relacionar religión y política. Rémora que tiene su origen en un doble descrédito: el descrédito de una política cada vez más burocratizada y pragmática, reducida a una resolución técnica de problemas y alejada de una comprensión global del hombre y de la sociedad, y el descrédito de unas iglesias puestas a la defensiva y desconfiadas, con tentaciones de replegarse sobre sí mismas o de actuar sólo en reivindicación de privilegios de grupo. Naturalmente, sin que ni uno ni otro diagnóstico abarquen la totalidad de los políticos y de las instituciones políticas ni la totalidad de las iglesias y de las instituciones eclesiales.

\section{b) La dificultad de fondo}

En todo caso, tales dificultades serían más bien coyunturales. La verdadera dificultad, para un discurso que relacione cristianismo y política, sigue proviniendo, a nuestro entender, de la diversidad de concepciones sobre la naturaleza del pensamiento cristiano cuando habla de los problemas sociales y políticos y de la diversidad de concepciones sobre el carácter de las relaciones de las iglesias con la sociedad y sobre la acción de los creyentes en la misma. Problemas que tienen una dimensión teológica (en tanto que afectan a la inteligencia de la fe) y una dimensión cultural e histórica (en cuanto que, en cada sociedad histórica, tal relación ha podido y puede ser diversa).

La pregunta más de fondo atañe a la legitimidad misma de un pronunciamiento 
del pensamiento cristiano sobre los problemas sociales. A la hora de abordar los problemas sociales ¿qué aportación puede realizar un pensamiento cristiano? ¿No tienen tales problemas, por su mismo carácter, un planteamiento y unas soluciones de tipo exclusivamente técnico, social, político y ético? ¿No es improcedente examinar las propuestas de solución a los problemas humanos según que las mismas provengan de creyentes o no creyentes, de personas que se confiesan religiosas o ateas?

Efectivamente, de entrada parece improcedente examinar las propuestas de solución de los problemas sociales desde otro referente que el hombre mismo. Son las necesidades y los valores históricamente reconocidos como humanos los que han de determinar lo que es bueno y malo para el hombre. Ciertamente entre esas necesidades y valores históricamente reconocidos como humanos está la religión. Pero es el bien del hombre el que se constituye en referente y discriminante de todo lo demás. Y a ese criterio está sometida la misma religión: «el sábado está hecho para el hombre, no el hombre para el sábado»

Ello no significa solamente que la buena religión es la que acude a las necesidades humanas sino también que las propuestas inspiradas en la experiencia religiosa de la realidad tienen que tener, como referente último, los valores históricamente reconocidos como humanos. La religión no puede determinar, ni menos imponer, de manera dogmática, lo que es bueno o malo para el hombre.

La experiencia religiosa de la realidad y la cosmovisión, la comprensión del hombre y de la sociedad que ella conlleva, se insertan hoy en una sociedad pluralista, donde convive con otras experiencias y otras cosmovisiones. El pensamiento religioso noes el único con capacidad de producción de significados sobre la vida humana y la sociedad y con capacidad de integración social. En una sociedad pluralista, la comprensión y las propuestas de solución de los problemas sociales inspiradas en el cristianismo no pueden ser presentadas de manera dogmática, como si fueran portadoras de la única y universal respuesta a los problemas humanos, sino que se hallan necesariamente en confrontación y diálogo con otras comprensiones. Tampoco tales propuestas han de convertirse en doctrina. El carácter de doctrina está en dotar al pensamiento social cristiano de una doble sobredeterminación: la que proviene de la autoridad y la que proviene de la sacralización. La legitimidad de una inspiración particular, todo pensamiento la tiene, no puede significar hacerse inaccesible a la crítica y a la controntación. 
En una sociedad democrática, pluralista y secularizada, como la nuestra, tales propuestas concurren con otras comprensiones y propuestas de solución. Su legitimación, su valor y su viabilidad no pueden fundamentarse en razones exclusivas de autoridad o sacralidad. Su comprensión de la realidad puede tener un interés general, no limitado a los creyentes, pero tal interés ha de estar fundado en su valor intrínseco y en su capacidad de crear un consenso.

\section{II. ¿Qué es la teología de la liberación?}

Generalmente, se denomina Teología de la Liberación (1) a un conjunto de escritos teológicos que desde 1970 fueron elaborándose en América Latina por autores como Gustavo Gutiérrez (Perú), Juan Luis Segundo (Uruguay), Hugo Assmann, Joseph Comblim, Leonardo Boff y Clodovis Boff (Brasil), Segundo Galilea, Ronaldo Muñoz, Pablo Richard (Chile), José Miguez Bonino, Juan Carlos Scannone, Enrique Dussel (Argentina), Ignacio Ellacuría y Jon Sobrino (El Salvador), por no nombrar sino algunos de los más conocidos.

La TL constituye una contribución a la búsqueda de solución de los complejos problemas sociales, económicos y políticos desde unas propuestas inspiradas en el cristianismo. Contiene, por ello, una contribución al pensamiento social cristiano, en su sentido amplio, y a la doctrina social de la iglesia, en su sentido más específico. En nuestra opinión, contribuye al enriquecimiento, a la pluralidad y a la democratización del pensamiento social cristiano.

\section{La TL es teologia}

Los teólogos de la liberación reivindican de manera inequívoca que lo que hacen es teología. Y toda teología es, en último término, un lenguaje sobre Dios. El discurso teológico se distingue claramente de los análisis sociales o cualquier otra opción, teórica o práctica, de la que se sirva la teología:

«Si bien es importante y urgente tener un conocimiento serio de la pobreza en que vive la gran mayoría de nuestro pueblo, así como de las causas que la originan, el trabajo teológico propiamente dicho comienza cuando

(1) Usaremos en adelante las siglas TL. 
intentamos leer esa realidad a la luz de la Palabra. Ello implica ir a las fuentes de la revelación» (2).

La TL, como veremos, no es entendible sin una opción por los pobres, pero Gustavo Gutiérrez aclara la raíz última de esa opción en la TL:

«El motivo último del compromiso con los pobres y oprimidos no está en el análisis social que empleemos, en nuestra compasión humana o en la experiencia directa que podamos tener de la pobreza. Todas ellas son razones válidas que juegan sin duda un papel importante en nuestro compromiso, pero en tanto que cristianos él se basa fundamentalmente en el Dios de nuestra fe. Es una opción teocéntrica y profética que hunde sus raices en la gratuidad del amor de Dios y es exigida por ella» (3).

Aquíno vamos a analizar la Th en cuanto teología, sino las aportaciones de ese discurso teológico a la comprensión de los problemas sociales. Conviene, no obstante, dejar afirmado que ninguna interpretación reductiva, del tipo la teología de la liberación no es más que (un pensamiento sociológico o político o un compromiso cristiano, un pensamiento ético o moral, o una espiritualidad) hace justicia a la misma. La TL no es, sin más, una reflexión sobre la liberación, aunque esa reflexión pudiera ser teológica por su inspiración cristiana:

«la teología de la liberación no es una reflexión teológica sobre la liberación, sino una reflexión sobre Diosen un contexto de liberación» (4).

Toda teología cristiana busca que sus afimaciones conecten coherentemente con una genuina interpretación de la Biblia y del acontecimiento Jesús de Nazaret. X busca la coherencia de sus afirmaciones con la fe de una Iglesia. Es impertinente a nuestro estudio, el examen de la TL bajo la perspectiva de su

(2) G.Guterrez(1989), Teologia de la liberación.Perspectivas, Súgueme, Salamanca, (14ed.), p. 27.

(3) Lbd., pp. 29-30.

(4) P. RICHARd, «Teología en la Teología de la Liberacion», en l. Ellacuria y J. Sobrino (eds.) (1989), Mysterium Liberationes. Consceptos fundamentales de la Teología de la Liberación, Trotta, Madrid, p. 20 . 
fidelidad a las fuentes bíblicas, o de su coherencia con la comprensión de la fe contenida en la tradición y en el magisterio de las iglesias cristianas.

Desde luego así lo creen los teólogos de la liberación y tal creencia se ve confirmada por la adhesión que tal teología suscita entre los creyentes de diversas latitudes.

\section{Hecha en un contexto de liberación}

El lenguaje de la liberación no es original de la teología. Surge del contexto latinoamericano de la década de los sesenta. Ese contexto tiene una doble referencia: sociopolitica y eclesial.

\section{a) El contexto sociopolítico}

El lenguaje de la liberación se aplica simultáneamente a diversos ámbitos en América Latina. En el ámbito socioeconómico sustituyendo al lenguaje del desarrollo. Las teorías de la dependencia (5) comenzaron a explicar la situación de los países desarrollados del centro y los países subdesarrollados de la periferia, no como diversos estadios coyunturales de un desarrollo lineal, sino como situaciones interdependientes que correlacionaban casualmente el desarrollo del centro y el subdesarrollo de la periferia.

En el ámbito político el lenguaje liberador reivindicaba una doble emancipación: soberania frente al imperialismo y a las formas mútiples de colonización y cambio radical al interior de los propios países (revolución frente a reformismo). Ello inspira los diversos movimientos de liberación nacional -guerrilleros, foguistas o populistas-que surgen en varios países latinoamericanos, con desigual éxitoen la consecución de un cambio, generalmente entendido como tránsito hacia alguna forma de socialismo.

En el ámbito cultural, liberación se opone tanto a colonialismo como a

(5) Sobre las teorías de la dependencia, iniciadas por los teónicos de la CEPAL, Fernando H. Cardoso, Andrés Gunder Frank. Theotonio dos Santos y Anibal Quijano, entre otros, puede verse la reseña bibliográfica de G. Arroyo. «Pensamiento latinoamericano sobre subdesarrollo y dependencia externa», en: Instituto Fe y Secularidad (1973), Fe cristiana y cambio social en América Latina, Sígueme, Salamanca, pp. 305-321. 
domesticación por el sistema y reivindica latinoamericanizar la cultura y recobrar los valores culturales autóctonos. Quizá el movimiento de educación liberadora de Paulo Freire sea una de sus manifestaciones más notorias (6).

De esa conciencia continental de dependencia y opresión surgen una serie de fenómenos que se identifican con el concepto de liberación, entre los que hay que situar a la teología del mismo nombre.

La raíz principal del lenguaje de liberación es la toma de conciencia de una pobreza generalizada y el análisis de las causas de esa pobreza como dependenciaeconómica, política, cultural, tecnológica e incluso religiosa en que viven los países subdesarrollados. El subdesarrollo de los países pobres se analiza como subproducto del desarrollo de los países ricos, como resultado de un proceso histórico de dominación, opresion y expolio, y los países subdesarrollados son considerados, no como países simplemente atrasados, sino como países empobrecidos, mantenidos en el subdesarrollo e injustamente privados de su propio proceso de crecimiento:

«El lenguaje de liberación no es otra cosa en su esencia que el correlativo político del lenguaje socio-analítico de la dependencia» (7).

b) El contexto eclesial

Pero el factor que hay que considerar más determinante en el nacimiento de la TL en América Latina es la presencia de sectores cristianos en el proceso de liberación. Es lo que G. Gutiérrez ha llamado en repetidas ocasiones el hecho mayor de la vida de la Iglesia latinoamericana.

Un sector significativo de la Iglesia latinoamericana-compuesto por comunidades de base, movimientos apostólicos de acción católica, estudiantes y obreros cristianos, agentes de pastoral obrera, campesina y urbana y un número no pequeño de sacerdotes, religiosas y religiosos y aun de obispos- se empezaba a situar al lado de los pobres y sus luchas. Este movimiento es anterior a la aparición

(6) P. Frenre (1969), Educación como práctica de la libentad, Icira, Santiago de Chile; ld., Pedagogía del oprimido, Tierra Nueva, Montevideo, 1970.

(7) H. Assmann (1973), Teología desde la praxis de liberación. Ensayo teológico desde la Américadependiente, Ś́gueme, Salamanca, 109. 
de las primeras obras de la TL.

Parece obvio que no era una nueva doctrina teológica lo que causaba tanta inquietud en el Vaticano y a la vez en el Pentágono (8), sino un auténtico movimiento social dotado de dinamismo emancipador.

¿Cómo explicar el nacimiento de este movimiento tan amplioen medio de una tradición eclesial conservadora y espiritualista y de una iglesia generalmente alineada con el poder establecido y más preocupada por el más allá que por los problemas reales que afectaban a la población latinoamericana? ¿Por qué surge en la Iglesia latinoamericana en un momento histórico determinado: a comienzos de los años sesenta?

Sin el proceso de apertura al mundo que significó para la Iglesia católica la celebración del Concilio Vaticano II (1962-1965) y sin las nuevas corrientes teológicas, anteriores y posteriores al mismo, así como el desarrollo de ciertas formas de cristianismo social, no es posible entender el desbloqueo eclesial latinoamericano que da origen a la TL y al movimiento cristiano que está en su base.

El nuevo movimiento social cristiano surge entre los grupos que se encuentran en la intersección de esos dos contextos: entre los movimientos laicales y cierto número de sacerdotes, religiosas y religiosos que se plantean estar encarnados y participar activamente entre la juventud estudiante, los barrios periféricos, los sindicatos rurales y urbanos y las comunidades de base. Este proceso de radicalización de la cultura católica latinoamericana, que va a desembocar en la TL, surge desde la periferia de la institución eclesial hacia el centro. Insertos de lleno en la sociedad en crisis, estos grupos fueron los más permeables a las corrientes sociales, políticas y culturales del entorno.

A partir de los años sesenta, ese movimiento de base se convirtió en lugar

(8) El documento Una nueva política interamericana para los años 80 (preparado por un grupo de expertos del Partido Republicano para la campaña del candidato presidencial Ronald Reagan) se pronuncia así sobre el tema: «La política exterior de los EE.UU tiene que empezar a enfrentarse (y no simplemente a reaccionar a posteriori) con la teología de la liberación, tal como es utilizada en América Latina por el clero de lateología de la liberación. En América Latina, el papel de la Iglesia es vital para el concepto de libertad política. Desgraciadamente, las fuezas marxistas-leninistas han utilizado a la Iglesia como arma política contra la propiedad privada y el sistema capitalista de producción, infiltrandola comunidad religiosa de ideas más conunistas que cristianas» (Comité de Santa Fe, 755) 
social de un compromiso cristiano activo en las luchas populares y también en el lugar de una reinterpretación del evangelio a la luz de aquella práctica. En algunos casos, el movimiento llega a ganar el centro e influye en las conferencias episcopales (especialmente la brasileña) y las órdenes religiosas, y tiene una incidencia decisiva en la Segunda Conferencia del Episcopado Latinoamericano celebrada en Medellín (1968).

Este movimiento, que no he pretendido describir sino insinuar, es el que da origen a un nuevo pensamiento teológico. En cierto sentido, la TL es el producto espiritual de ese movimiento cristiano o, comola llama G. Gutiérrez, «la expresión del derecho de los pobres a pensar su fe» (9); pero, a la vez, al legitimarlo y dotarlo de un pensamiento teológico coherente, la TL contribuyó enormemente a su extensión y a su reforzamiento. Los teólogos de la liberación, que participan y se encuentran insertos en el mismo movimiento, repiensan la fe desde su propia experiencia y la experiencia colectiva, actuando como intelectuales orgánicos de la iglesia de los pobres (10).

La Asamblea Episcopal celebrada en Medellín constituye un hito en la historia de la Iglesia latinoamericana. Concebida con el objetivo de una adaptación del Concilio Vaticano II a la Iglesia del continente, una nueva sensibilidad aflora en sus documentos: la opción por los pobres, el análisis de la situación de subdesarrollo como dependencia y como situación estructural de pecado y la dimensión histórica de la fe son sus temas privilegiados. Pero sobre todo en esos documentos se refleja la conciencia de vivir un momento histórico privilegiado en el que el clamor de los pobres y la necesidad de un cambio de la situación se imponen en la conciencia de la Iglesia latinoamericana.

\section{Una nueva forma de hacer teología}

La teología, decíamos, es un discurso sobre Dios. Ahora bien, ese discurso, junto a las fuentes bíblicas, la tradición y el magisterio, y junto a determinados instrumentos metodológicos, supone siempre un contexto, una situación determi-

(9) G.Gutiérrez (1990), Teología de la liberación. Perspectivas, Sígueme, Salamanca(14 ed.), p. 22.

(10) La conocida expresión de Antonio Gramsci es citada y aplicada at teólogo por G. Gutrérez (1973), Teología de la liberación. Perspectivas, Sígueme, Salamanca, p. 37. 
nada desde la que se pronuncia. Los teólogos de la liberación han interpretado la fe desde la experiencia de unos cristianos comprometidos en una praxis de liberación y han interpretado la fe cristiana para esa experiencia.

Con la misma fuerza con que reivindican el carácter teológico de su discurso, reivindican la incidencia de un tal contexto en su teología. Esa incidencia significa que ese discurso sobre Dios, pronunciado en un contexto de liberación, se modula de manera sustancial, hasta el punto de afectar a la concepción misma de la tarea teológica. Es la misma experiencia cristiana y, por ello, la teología que la interpreta, la que queda mediada por la experiencia del contex to de liberación.

Ello desemboca en un nuevo método teológico:

«En la teología de la liberación hay dos intuiciones centrales que fueron además cronológicamente las primeras, y que siguen constituyendo su columna vertebral. Nos referimos al método teológico y a la perspectiva del pobre. Desde un comienzo la teología de la liberación planteó que el acto primero es el compromiso de liberación y que la teología viene después, como acto segundo» (11).

«Si la teología es una reflexión desde y sobre la praxis, es importante tener presente que se trata de la praxis de liberacion de los oprimidos de este mundo. Aislar el método teológico de esta perspectiva es perder el nervio de la cuestión y recaer en el academicismo. No basta decir que la praxis es el acto primero, es necesario considerar el sujeto histórico de esa praxis: los hasta ahora ausentes de la historia. La teología así entendida arranca de las clases populares y desde su mundo: discurso teológico que se hace verdad, se verifica, en la inserción real y fecunda en el proceso de liberación» (12).

Desde el punto de vista teológico, cabe situar ahi la primera aportación específica de la TL al pensamiento social cristiano: aun en otros contextos, el lenguaje de la liberación es hoy casi universal en el lenguaje teológico.

(11) G. Guterrrez (1982), La fuerza histórica de los pobres. Sígueme, Salamanca, p. 257.

(12) Ibd., p. 258 


\section{TII. Aportaciones all pensamiento social cristiano}

\section{Pensar desde los pobres}

La preocupación por la situación de los pobres se halla en toda la tradición cristiana y constituye un hilo conductor central, aunque no único, en la Biblia y los primeros teólogos de la Iglesia. Y precisamente en el sentido de hacer sólo así una práctica correcta de la fe y la experiencia religiosa.

Pero en la TL hay una nueva experiencia del pobre que es la que le confiere su auténtica novedad:

«Quien no tiene la experiencia del pobre, tal como ella se presenta hoy dia (realidad colectiva, conflictiva y activa), no reúne las condiciones epistemológicas adecuadas para comprender y menos para producir una verdadera teología de la liberación» (13).

Al hablar desde los pobres, los teólogos de la liberación incorporan una doble tradición: bíblica y marxista.

El análisis de la pobreza y sus causas revela su dimensión estructural. La pobreza y la situación de los pobres son el fruto de situaciones y estructuras, tanto nacionales como internacionales, que se relacionan causalmente con la riqueza de unos pocos y la dependencia de las naciones pobres respecto de las ricas. Su conocimiento remite, por tanto, a causas económicas, sociales y políticas estructurales.

El análisis hace también descubrir al pobre como perteneciente a una colectividad (una clase social, una nación dependiente, una cultura marginada, una raza o un sexo discriminados). Frente a la concepción que hace de los pobres aisladamente un objeto de la caridad o asistencia paternalista; frente a la concepción meramente moralizante que hace de la pobreza un problema de justicia, la dimensión más nueva, y más rica en consecuencias, es la posición política del problema de la pobreza.

Como consecuencia de ello se percibe la conflictividad de la solidaridad con

(13) Cl. BOFF (1990), Théorie et pratique. La méthode des theologies de la libération, Les Editions du Cerf, Paris, p. II. 
los pobres y la acción contra la pobreza. Aquí es donde la TL se encuentra con el marxismo como una explicación sistemática, coherente y global de las causas de la pobreza, y como una propuesta históricamente concreta y radical para su abolición. La teología concibe la situación de pobreza como situación estructural de pecado. Ahí está la raíz última de la pobreza. Pero esa estructura de pecado necesita del análisis de las ciencias sociales para determinarse y de la acción política para superarse.

La conflictividad inherente a una tal opción toma como por sorpresa a una institución como la eclesial, acostumbrada a un tratamiento más bien irénico de los problemas sociales. La opción por los pobres supone una opción que tiene connotaciones sociales y políticas frecuentemente conflictivas.

El pobre, categoría epistemológica

Pero lo más novedoso de la TL es hacer de la experiencia del pobre la experiencia teologal fundamental, es decir, concebir lo que es Dios y lo que es ser creyente a partir de esa experiencia.

Pensar desde los pobres aporta una nueva clave de lectura de la realidad. Supone comprender la realidad toda desde el lugar de la opresión y desde la tarea histórica de la liberación de los oprimidos. Partir del pobre significa un nuevo modo de ver las cosas, un nuevo modo de conocer. Esta experiencia básica es la que genera una nueva conciencia, en cuya radical originalidad los teólogos de la liberación nunca creen insistir demasiado.

Gustavo Gutiérrez califica esta nueva conciencia como una manera distinta de percibirnos como hombres y como cristianos y de salto cualitativo (14). Pero la expresión más rotunda al respecto nos parece ésta de Hugo Assmann:

«Todas las determinaciones tradicionales de la conciencia cristiana, anteriores o ajenas a esta nuestra experiencia, revelan súbitamente la precariedad y la insuficiencia de sus criterios» (15).

(14) G.GuTtérRez (1973), Evangelio y praxis de liberación, en AA.VV.,Fe cristiana y cambio social en América Latina, Sígueme, Salamanca, p. 240.

(15) H. Assmanw, Teologia desde la praxis..., o.c., p. 27. 
Laadopción del pobre como categoría epistemológica significa, precisamente, que, partiendo de los pobres, se pasa a percibir, analizar e interpretar la realidad de nueva manera. Los teólogos de la liberación traducen en categorías teologicas esa nueva manera de ver la realidad desde la experiencia del pobre.

\section{Pensar desde la práctica}

Partir del pobre es, también, partir de su lucha por la liberación. Es una nueva manera de insertarse en la realidad histórica. Lo que postula de hecho un nuevo modo de hacer teología es el compromiso de los cristianos en el proceso de liberación. La relación histórica de los cristianos con la liberación es lo que demanda una relación nueva de la teología con la práctica.

Así, es imposible conocer cuál es el aporte específico cristiano a la liberación previamente a comprometerse con ella. El paso no es del Evangelio a la liberación sino de la liberación al Evangelio. La interpretación de éste variará según se lo mire desde fuera o desde dentro del compromiso liberador. No se trata de redefinir la práctica social desde los valores evangélicos sino de hallar la significación histórica del evangelio a partir de la práctica social.

La pregunta fundamental de la TL es qué significado tiene la liberación cristiana para el hombre concreto marginado y oprimido cuya necesidad fundamental es una tarea efectiva de liberación. El significado liberador de la fe cristiana ha de verificarse, ha de tener un carácter práctico y real, ha de comprobarse de alguna forma en la propia realidad histórica. La respuesta a esa pregunta ha de tener además carácter concreto: dicho hombre se encuentra en la necesidad de optar por un sistema u otro de transformación de la realidad histórica.

La limitación de gran parte de la teología ha sido su idealismo. Habla sí de salvación, pero a la hora de concretar tal salvación se desvincula de la realidad histórica, sumiéndose en un espiritualismo alienante o remitiendo la verificación de dicha salvación únicamente a su dimensión trascendente. Según la TL la salvación cristiana ha de hacerse histórica. Y al hacerlo entra en relación con las realizaciones históricas liberadoras.

La prioridad concedida a la práctica está, pues, en consonancia con la centralidad de los pobres. En esa misma línea se inscribe la reivindicación de la ortopraxis frente a la ortodoxia: 
«En álima instancia, en efecto, la verdadera interpretación del sentido desvelado por la teología se da en la praxis histórica» (16).

Pero en el tema de la praxis, la TL incorpora también la doble tradición bíblica y marxista. La referencia explicita a la tradición marxistaqueda suficientemente recogida en estas frases de Ion Sobrino:

«a función liberadora del conocimiento no consiste en explicar o dar significado a una realidad existente, ni a la fe amenazada por la situación, sino en transformar una realidad para que llegue a tener significado y recuperar de ese modo el sentido perdido o amenazado de la fe... En este sentido, todavía muy genérico, es evidente la influencia de Marx para la misma comprensión del conocimiento teológico. Su famosa Tesis XI sobre Feuerbach aparece como el paradigma de la esencia liberadora del conocimiento» (17).

La importancia de la práctica y la verificación en ella de la auténtica fe constituyen una tradición del pensamiento cristiano. Pero la praxis histórica dota de un nuevo horizonte a la teología, en oposición al horizonte cosmológico de la teología clásica y al horizonte de la subjetividad propio de la teología moderna. Ello supondrá un cambio en el universo conceptual en el que se mueve la teología. Las ciencias sociales y la política van a ocupar el lugar privilegiado, reservado anteriormente a la filosofia, entre las mediaciones del pensamiento teológico.

Hay aquí una contribución especifica de la TL al pensamiento cristiano: el haber hecho de la praxis histórica un punto de partida y un condicionamiento central para la reflexión teológica.

\section{Pensar en clave política}

Transformar la realidad en función de la liberación de los pobres es una tarea política. El término liberación pertenece originariamente a las categorías políticas. No tiene sentido hablar sobre Dios en ese contexto sin dotar a la teología

(16) Mbd., p. 38 .

(17) J. Sobrino (1984), Resurrección de la verdadera Iglesia, Sal Terrae, Santander, p. 30. 
de una clave hermenéutica política. Ello significa que el paradigma político es una clave de lectura de la fe cristiana desde la realidad y de la lectura de la realidad desde la te cristiana. L a teología que quiera estar inserta en la realidad ha de ser una teología política, ya que la realidad es política en su plano más decisivo.

La primera TL ha de ser considerada como una teología política, una foma latinoamericanade teología política:

«Definiéndose como reflexión crítica sobre la praxis histórica de liberación en el sentido de toma de cuerpo de la fe, la teología de la liberación se presenta explicitamente como una forma latinoamericana de teologia política» (18). .

Laantigua teología politica tuvo históricamente una doble connotación: obien la de servir de ideología sacralizante para una estructura política, o bien la de realizar una politización directa de los postulados de la te, de manera fundamentalista. $\mathrm{El}$ ideal de dicha teología se expresó como cristiandad: en la modalidad de un poder directo de la Iglesia sobre la sociedad o en la de una situación privilegiada desde la tutela del poder civil, a quien a su vez la Iglesia servía de legitimación. La vieja teología política es la teoria que intenta, desde la época de la llustración, restaurar la figura del Estado cristiano.

Lanueva teología política, iniciada en Europa por el teólog@ alemán J.B. Metz (19) y seguida por otros reconocidos teólogos europeos, tiene un nuevo planteamiento:

« La mueva teología política significa el esfuerzo de reflexión crítica sobre las relaciones de la fe cristiana con la sociedad. Aun diferenciándose de la vieja teología política piensa que la relación fe-política no puede resolverse con un repliegue de la religión sobre símisma. Se trata de una

(18) H. Assman, Teologia desde la praxis de la liberación..., o.c., p. 24, donde remite en nota a los escritos de G. GuTterrez.

(19) Véanse, entre sus muchos libros y artículos: J.B. Merz (1970), Teología del mundo, Sígueme, Salamanca; Id. (1979), Lafe en la historia yen la sociedad. Esbozo de ana teología política fundamental para nuestro tiempo, Cristiandad, Madrid; Id. (1982), Más allá de la religión burguesa. Sobre el futuro del cristianismo, Herder, Barcelona. 
teología que quiere permanecer cristiana sin evadirse de sus responsabilidades ante la realidad» $(20)$.

La teología política europea parte de la distinción entre Estado y sociedad y no pretende la configuración de aquél desde las determinaciones cristianas. Se trata más bien de despertar la conciencia de las implicaciones y obligaciones sociales del cristianismo en la situación histórica y cultural posterior a la Ilustración. Por consiguiente, de poner a la Iglesia y a la teología en relación con la historia de la libertad de la sociedad moderna. Constituye, por tanto, una reflexión crítica sobre la Iglesia y la sociedad y una hermenéutica política del evangelio.

Los primeros pasos de la TL son semejantes a los de la teología política europea. Son una crítica de la teología establecida en cuanto actúa como ideología del sistema dominante, causante de la situación de opresión y dependencia del pueblo latinoamericano.

Enseguida, sin embargo, va a perfilarse un distanciamiento de la TL respecto de la teología política europea. La TL descansa sobre la percepción de otro desafío diferente al de la modernidad: el desafío del dolor y la humillación de los pueblos latinoamericanos, el desafío de la pobreza y la ausencia de vida.

A nuestro entender, tal diferencia se sustancia en los diversos contenidos que entrañan los términos libertad y liberación. La percepción de la dimensión política de la realidad, el predominio de lo que Gustavo Gutiérrez llama la razón política, es común a ambas teologías. En ambas hay también un ensanchamiento hermenéutico de la teología a lo político. Pero mientras que, para la teología política europea, el concepto de ese ensanchamiento está en la libertad, para lá teología de la liberación tal ensanchamiento queda en lo abstracto si no llega al de liberación:

«En el contexto del lenguaje cristiano usual, la introducción del término liberación representa un dislocamiento del eje semántico de la palabra libertad. Observar eso nos parece sumamente importante porque nos muestra en un ejemplo concreto la ocupación, la dominación, el aprisionamiento ideológico-semántico de nuestro lenguaje. La teología europea,

(20) J. Moltmann (1974), Ilustración y teoria teológica, Sígueme, Salamanca, p. 25. 
aun la más progresista, continúa ignorando la palabra liberación, pero habla mucho de libertad. Nuestras traducciones de la Biblia, en todas las lenguas, usan el término libertad» (21).

Sin el compromiso real con los oprimidos, o dejando en la sombra ese dato, las reivindicaciones o críticas de la teología política se reducirían a expresiones ideológicas y polémicas o se quedarían en mera literatura.

El diálogo libertad-liberación, como síntesis de la diversa ubicación de la teología política europea y de la TL, explica tanto la crítica de la teología de la liberación a la teología europea como la crítica a la modernidad contenida en la TL.

Para toda teología los datos de la realidad social e histórica son imprescindibles para la experiencia de la fe. La misma revelación, no llega al hombre sino través de la experiencia social e histórica de quienes la transmiten. Los teólogos de la liberación tienen el convencimiento, fundamentado en su experiencia, de que el hecho mayor de la historia de nuestro tiempo es la opresión en que se encuentran los pobres y su ansia de liberación. Y que es necesario articular sobre ese eje la visión de la historia y de la sociedad.

La teología europea habría acertado al considerar importantes el desde dónde y el para quién de la reflexión teológica, pero habría errado al situarse, como punto de partida, en el europeo ilustrado o postilustrado, cuando la ubicación correcta es, para la TL, en el pobre y en los excluidos de la historia. Excluidos precisamente, en parte, por la propia tradición ilustrada. Por eso la TL la acusa de haberse olvidado del requisito fundamental hoy día para poder realizar una teología crítica y realista, fiel a la vez al mensaje bíblico y a la realidad histórica actual: la existencia de pueblos oprimidos y excluidos, de razas subyugadas y sometidas, de culturas marginadas, de colectivos explotados, es decir, de haberse olvidado de los pobres.

\section{Pensamiento mediado por las ciencias sociales}

Transformar la realidad en función de la liberación de los pobres exige conocerla a través de instrumentos adecuados. La teología no dispone de tales

(21) H. Assmann, Teologia desde la praxis de la liberación, o.c., p. 32. 
instrumentos. Es, por ello, imprescindible el recurso a las ciencias sociales. Ahora bien, la utilización del análisis social despierta a la teología de su sueño dogmático, de su ingenuidad y de su inocencia social y política.

Las ciencias sociales no son neutrales. La incorporación de un determinado análisis sociopolítico no es sólo una opción científica sino que, frecuentemente, entraña una opción ideológica y política. Ello no debe hacer a la teología desistir de tal mediación para volver al reino de lo meramente ideal, universal y ahistónico; pero ello impone a la teología un discernimiento y una modestia.

En la TL se trata de articular una lectura teológica de la realidad a partir de los pobres y en vistas a su liberación. Hay, por tanto, que comenzar por informarse de las condiciones reales de los pobres y las causas de su pobreza, de las formas de opresión y de sus causas. La mediación de los análisis sociales es una exigencia misma de la praxis de la fe, en cuanto ésta quiere ser una fe encarnada y una praxis eficaz.

Ahora bien, la asunción del análisis social no se realiza de forma acrítica. La teología no es en esto neutral. Exige un discemimiento de los métodos y enfoques del análisis social y la elección de aquellos análisis que describen de manera más global y radical la realidad tal como ella aparece también a la luz de la fe. Todos los teólogos insisten en la distancia crítica de la teología respecto de los análisis sociales.

Lo que podría parecer una simple afirmación liena de lógica y sentido común (que también la teología para actuar sobre la realidad necesita conocerla) no aparece, sin embargo, exento de dificultades. ¿Cuál es la articulación y la modalidad de relación entre la teología y las ciencias sociales? ¿En qué sentido esa relación es distinta de la relación de la teología, en general, con la ciencia? Preguntas que nos remiten a la concepción epistemológica de la TL y que no es posible abordar en este trabajo.

La mediación del análisis social suscitó uno de los puntos más polémicos en relación a la TL: su asunción, al menos en parte, del análisis marxista. Un tema frecuentemente tratado desde posiciones de impugnación o defensa.

Hoy resulta poco comprensible tanto la persistente acusación de marxismo a la TL como la propia línea argumental de los teólogos de la liberación a la hora de reivindicar la legitimidad de su utilización del marxismo.

Los teólogos de la liberación, como podría decirse de muchos otros teólogos y de muchos pensadores contemporáneos, han asimilado una parte del arsenal 
teórico marxista. Hay una serie de conceptos, análisis y puntos de vista marxistas que juegan un papel importante en su comprensión de la realidad, y concretamente en su comprensión de la realidad latinoamericana. Pero al igual que lo juegan en el pensamiento actual otros fenómenos culturales o científicos, como la llustración o la teoría de la evolución:

«la teología política es una teología bajo el signo de Marx, en igual sentido como la escolástica fue una teología bajo el signo de Aristóteles y la teología protestante liberal lo fue bajo el signo de Kant» (22).

La postura expresa de todos los teólogos de la liberación es que la utilización de contenidos teóricos marxistas no significa, sin más, una adopción del marxismo. La mayoría de ellos hablan del marxismo como de una ciencia social que es utilizada, de manera estrictamente instrumental, para mejor conocer la realidad latinoamericana.

\section{Súntesis y evaluación}

La teología de la liberación ha entendido que hacer hoy una adecuada teología, pasa porque el lenguaje y el mismo quehacer teológico sea una actividad mediada por el compromiso, por el análisis social y por la acción sociopolítica. ¿Qué significa esa mediación? Significa que no basta hablar de la significación del cristianismo para el hombre genérico (la humanidad) o para el hombre o la mujer individualmente considerados, sino que hay que hablar de su significación para los hombres y mujeres colectivamente inmersos en las determinaciones historicas -sociales, políticas, económicas y culturales- y para la práctica de transformación que se da en esas determinaciones.

La fe cristiana en Dios no adquiere su sentido real en términos, únicamente, de un marco interpretativo de la realidad o de una salvación individual o de una consumación escatológica, sino también en términos de an marco histórico de transformación de la realidad en función de la lliberación de los pobres.

Muchas de las reivindicaciones epistemológicas de la TL, y la central de la

(22) A. Fikrro (1975), El Evangelio beligerante, Verbo Divino, Estella, p. 102. 
función práctica del conocimiento, pertenecen hoy a los supuestos generales de la ciencia y la cultura contemporáneas, con independencia de la conciencia, refleja o no, de su extracción marxista. La TL traslada esta concepción práctica del conocimiento a la teología como necesidad de vinculación de la fe con la praxis, como prioridad de la ortopraxis respecto a la ortodoxia.

Tal vinculación y prioridad arranca del mismo evangelio y de la concepción bíblica de la religión verdadera frente a la religión cultual y a la religión como conocimiento.

El fracaso del proceso moderno de la libertad y la ilustración ha desembocado en el predominio de la razón instrumental, en la organización científicotécnica de la sociedad, en el vaciamiento de la libertad de los individuos y su sujeción a la manipulación, en el dominio de unos pocos países ricos sobre la mayoría de países pobres. Su reconstrucción como proceso a liberación parte de que el hombre como sujeto y la libertad no son posibles solamente como proceso en la conciencia, ya que no existe la libertad si ésta no es vivida en las instituciones y las estructuras.

Su llamada de atención sobre el punto de partida en los pobres, aun excluyendo las razones propiamente teológicas para ello, entronca con razones contempladas en la tradición marxista: son los oprimidos, en cualquier situación, los objetivamente más necesitados y los más interesados objetivamente en un proceso de liberación. Y sólo su libertad real, en cuanto sólo así puede hablarse de una libertad de todos, podrá dar por consumado aquel proceso.

Al hablar de los pobres como sujeto histórico (se determine éste como los pobres, los pueblos oprimidos o las minorías o mayorias excluídas) la TLentronca con una determinada tradición de filosofía de la praxis: la que une el análisis social con la interpretación de la historia y con la llamada a la movilización.

Desde este punto de vista, la evaluación de las realizaciones liberadoras que avaló la TL hay que hacerla desde la historia y desde la ciencia social y política. En cualquier caso hay que evitar que, al avalar como más cercanas a la liberación teológica determinadas opciones de análisis social o de realización política, tales opciones puedan aparecer sobredeterminadas por una impregnación de carácter mesiánico o sacralizado. Tal cosa ha podido ocurrir, por ejemplo, con la teoría de la dependencia o con la revolución sandinista. Y otro tanto con el carácter general revolucionario de los procesos de liberación. Pero ni la TL es menos verdadera después del hundimiento del comunismo, ni tal hundimiento hace 
menos necesaria y urgente la liberación de los pobres.

El contexto en que se concretó la exigencia metodológica de incorporar al discurso teológico la mediación del análisis social produjo, en los primeros teólogos de la liberación, una especie de fascinación por la teoría sociológica latinoamericana de la dependencia y en general por el marxismo como explicación de la situación empobrecida de sus países. Tal explicación es, sin duda, discutible. Pero también son discutibles otras opciones teóricas avaladas por el pensamiento social cristiano y el hecho de que, durante más de un siglo, haya mantenido una oposición cerrada y monolítica frente al marxismo, sin descubrir en él aportaciones válidas y sin reconocer su apoyo a los colectivos más oprimidos de la sociedad.

El pensamiento cristiano, en cuanto tal, no posee mediaciones propias o específicas para la realización del proceso de liberación. La TL entiende que se han de adoptar aquellas mediaciones que sean histórica y realmente eficaces para tal proceso, a la vez que acordes con los valores humanos que representa el cristianismo. En cualquier caso, la TL más reciente insiste en el carácter metodológico que tiene la mediación del análisis social y de la acción sociopolítica.

Algunos de los planteamientos sociopolíticos y de los análisis de que partió la TL están hoy desacreditados. Pensar, entonces, que la propia TL, ha quedado por ello obsoleta es no haberla comprendido. Los problemas a los que esos análisis y la propia TL buscaban dar solución no han hecho, desgraciadamente, sino agravarse.

La rapidez de los cambios hacen hoy más visibles a corto plazo la limitación y obsolescencia de ciertos análisis. Hay que evitar, sin embargo, el anacronismo de juzgar aquellos análisis a la luz de la evolución actual de la realidad y de los análisis sociales. La validez de una comprensión y de unas propuestas de solución de los problemas sociales no es determinable como asunto teológico. El pensamiento cristiano deberá discernir tanto su coherencia con los valores humanos contenidos en el cristianismo como la medida en que tal comprensión mantiene su vigencia teórica y eficacia histórica. Y en esta tarea es donde resultan ineludibles las ciencias sociales.

La controversia en torno a la teología de la liberación, sus entusiastas defensores en unos casos y sus no menos denodados detractores en otros, ha hecho difícil acercarse a ella prescindiendo de ese carácter polémico. Y hay que reconocer también que, en parte, la teología de la liberación llegó a ser más 
conocida en Europa gracias a esa controversia y al eco que tuvo en los medios de comunicación.

Es innegable que la teología de la liberación ha sido un fenómeno eclesial de importante significación extrateológica. Sin embargo, los teólogos de la liberación afirman, frente a sus detractores e incluso frente a algunos de sus defensores, que lo que han hecho es teología. Las preguntas que se formulan y a las que intentan dar respuesta nacen de la fe cristiana y se dirigen a la inteligencia y comprensión de esa fe. Eso sí, de una fe vivida en un determinado contexto.

La teología de la liberación no nace por generación espontánea: el suelo en que nace es América Latina y tiene una vocación latinoamericana, autóctona. De esa ubicación en un contex to determinado, el de América Latina y, en general, el de los pueblos del Tercer Mundo, nace su novedad y las aportaciones específicas que hace al pensamiento cristiano.

Culturalmente, la teología de la liberación conecta con la teología política centroeuropea, pero percibe el contraste de las condiciones humanas en que están inmersas tanto las distintas sociedades como la tarea teológica en Europa y en los pueblos del Tercer Mundo. Desde ese contraste, la teología de la liberación ha enriquecido a la teología europea y la ha sensibilizado sobre el hecho de que sus perspectivas no eran sin más universalizables.

Así, su óptica inicial se universaliza, reivindicando su punto de partida y su percepción como el determinante de la conciencia cristiana general y de la aportación del pensamiento cristiano a los problemas sociales. Su evolución posterior se sitúa en la percepción de la complejidad y pluralidad de sujetos desde donde se producen los cambios en la historia.

La aportación principal de la TL al pensamiento social cristiano y a la comprensión y propuestas de solución de los problemas sociales se halla en la comprensión del sentido de la historia desde los márgenes, desde los excluídos, desde el reverso de la misma y desde la praxis de liberación que tal comprensión conlleva. Los análisis sociales, las mediaciones políticas, los valores que se reivindican, el discurso sobre Dios que desde el pensamiento cristiano pueda pronunciarse, tendrán siempre como referencia, como legitimación y como verificación, el marco de transformación de la realidad en función de la liberación de los pobres. 